\title{
A influência de medicamentos antirretrovirais no tratamento sintomatológico da esclerose múltipla
}

\section{The influence of antiretroviral drugs in the sintomatologyc treatment of multiple sclerosis}

\author{
Cristine Souza da Rosa ${ }^{1}$ \\ Laura Vicedo Jacociunas ${ }^{1}$
}

\section{RESUMO}

A esclerose mútipla é uma das doenças desmielinizantes mais comumente estudada e teve um crescimento global da média do número de casos entre 2008 e 2013. A evolução clínica dá-se através de déficits e sintomas, ambos de cunho neurológico,que prejudicam a rotina e a qualidade de vida do portador da doença. 0 tratamento para a esclerose múltipla é feito através de fármacos imunossupressores e imunomoduladores. Estudos recentes associaram a melhora dos sintomas da esclerose múltiplaem pacientes que são soropositovos para HIV e que estão realizando tratamento para o víruscom os antirretrovirais. Há a hipótese de que esses medicamentos agem suprimindo a expressão de retrovírus endógenos humanos, incorporados ao genoma humano durante a evolução da espécie, e se investiga se estes estão associados ao desenvolvimento da esclerose múltipla. A fim de elucidar se há a eficácia de antirretrovirais no tratamento dos sintomas da esclerose múltipla, dados foram pesquisados na literatura científica. Neste estudo ficou claro que os antirretrovirais podem auxiliar os pacientes portadores de esclerose múltipla no que se refere a atenuação dos sintomas, principalmente nos quadros de surtos. Entretanto, mais pesquisas são necessárias para elucidar melhor estes processos, requerendo maior tempo de estudo e um número mais elevado de pacientes.

\section{PALAVRAS-CHAVE}

Esclerose múltipla; Terapia antirretroviral; HIV; Retrovírus endógenos.

${ }^{1}$ Centro Universitário Metodista - IPA. 


\begin{abstract}
Multiple sclerosis isoneofthe most commonly studied dem yelinating diseases and hadan overall increase in the average number of cases between 2008 and 2013. The clinical evolution occurs through deficits and symptoms, both of neurological nature, which impairs the routine and quality of life of patients with the disease.The treatment for multiple sclerosis is done throughim munosuppressive andimmuno modulatory drugs. Recent studies have associated improvement in the symptoms of multiple sclerosis in patients who are seropositive for HIV and who are undergoing treatment for the virus with antiretrovirals. Thereis a hypothesis that these drugs actby suppres singthe expression of humanendo genous retroviruses, incorporatedinto the humange nome duringthe evolution of the species, andinvestigating whether they are associated with the development fmultiplesclerosis. In order to elucidate whether there is an efficacy of antiretroviral drugs in the treatment of multiple sclerosis symptoms, data have been researched in the scientific literature. In thisstudy, it wasclearthatantiretroviralscan help patientswithmultiplesclerosis with regard to symptom attenuation, especially in outbreaks. However, more research is needed to better elucidate these processes, requiring more study time and a higher number of patients.
\end{abstract}

\title{
KEYWORDS
}

Multiple sclerosis; Antiretroviral therapy; HIV; Endogenous retroviruses. 


\section{INTRODUÇÃo}

A esclerose múltipla (EM) é uma das doenças autoimunes desmielinizantes mais comuns que acomete o sistema nervoso central (SNC). Sua etiologia é desconhecida e o risco de desenvolvimento pode ser determinado pela genética, assim como por fatores ambientais(WILDNER; SELMAJ, 2017). A prevalência da doença é heterogênea e de acordo com o relatório emitido pela Federação Internacional de Esclerose Múltipla(THOMPSON; BANEKE, 2013), houve um aumento da média global de trinta casos por cem mil habitantes em 2008 para trinta e três casos por cem mil habitantes em 2013 (LERAY et al., 2016; WALLIN et al., 2019). 0 desenvolvimento da EM é crônico e acomete adultos jovens entre 20 e 40 anos de idade, sendo mais frequente em mulheres. Esta patologia afeta a substância branca do SNC, causando múltiplas lesões na bainha de mielina, o que leva à falha na condução do impulso nervoso(CARDOSO, 2010).

0 curso clínico da doença ocorre em forma de episódios de surto e remissão,e tem duração variável de semanas a meses e caracterizando-se por déficits neurológicos, com recuperação gradual e parcial (DE ALENCAR SANTOS JÚNIOR et al., 2016; LUBLIN et al., 2014). Durante os surtos há sintomas como a perda total ou parcial de funções fisiológicas, como a diminuição da motricidade em uma ou mais partes do corpo, a diminuição da sensibilidade tátil, a deficiência visual, além devisão dupla e falta de coordenação de movimentos musculares voluntários (SÁ, 2012).

0 tratamento é basicamente realizado através de fármacos imunossupressores e imunomoduladores, o que reduz a ocorrência de surtos (TILBERY et al., 2009). Estudos com pacientes diagnosticados com o Vírus da Imunodeficiência Humana (HIV) e EM, observam que a terapia com medicamentos antirretrovirais (ARVs) pode reprimir o desenvolvimento da EM que já foi relacionado a outros vírus, tais como os Retrovírus Endógenos Humanos (HERVs), o vírus Epstein-Barr e o vírus Varicella zoster (CHALKLEY; BERGER, 2014; GOLD et al., 2015; KANG et al., 2011; MECHELLI et al., 2015; NEXØ et al., 2013).

O HIV é um retrovírus que tem como característica causar severa imunossupressão, deixando o organismo mais suscetível a infecções oportunistas, neoplasias se- cundárias e manifestações neurológicas. A transmissão é realizada através de troca de sangue ou líquidos corporais infectados pelo vírus, como: contato sexual, utensílios pérfuro-cortantes - especialmente em usuários de drogas injetáveis, transfusão sanguínea, bem como pela passagem do vírus de mães infectadas para o bebê, seja transplacentária ou via aleitamento materno(PARHAM, 2011; POLEJACK; SEIDL, 2010).0 vírus apresenta dois alvos principais de infecção: o sistema imunológico e o sistema nervoso central (COELHO, 2013; COSTA, 2013). No sistema imunológico há a depleção de células T CD4 causando a perda de função das mesmas levando a uma imunodeficiência, pois a molécula de superfície CD4 age como receptor para o HIV. Com o desenvolvimento da imunodeficiência humana, o organismo fica suscetível a infecções oportunistas (OKOYE; PICKER, 2013).Já no sistema nervoso central, o HIV se manifesta através do desenvolvimento de distúrbios neurológicos e cognitivos. 0 dano neuronal causado pela infecção parece ser em virtude da produção de produtos neurotóxicos, como espécies reativas de oxigênio, por células infectadas (CALCAGNO; DI PERRI; BONORA, 2017; MALIK; EUGENIN, 2016). 0 tratamento, com ARVs, já está bem estabelecido perdurando por toda a vida para suprimir a replicação viral (FORESTO et al., 2017).

Os medicamentos antirretroviais, para tratamento do HIV, são distribuídos gratuitamente pelo Sistema Único de Saúde (SUS) desde 1996, quando foi sancionada a Lei № 9.313 (BRASIL, 1996). No Brasil, Ministério da Saúde recomenda 19 medicamentos para uso no tratamento do HIV, a qual são descritas 4 classes. (I) inibidores da transcriptase reversa análogos de nucleosídeios (ITRN), que agem por um mecanismo competitivo com os nucleosídeos fisiológicos. São incorporados na cadeia do DNA do vírus, fazendo com que o alongamento do DNA seja interrompido, cessando a replicação viral. (II) inibidores da transcriptase reversa não análogos de nucleosídeos (ITRNN), que são fármacos inibidores da transcriptase reversa que atuam por um mecanismo não competitivo, estão ligados ao centro catalítico da transcriptase reversa, causando mudança conformacional na enzima e inibe a sua atividade de DNA polimerase, ambos dependentes de DNA e RNA. (III) inibidores de protease (IP) que têm sua ação farmacológica no final do ciclo de replicação do HIV, onde se ligam às proteases do vírus levando ao bloqueio das 
atividades proteolíticas da enzima, resultando na incapacidade da formação de virions infecciosos maduros. Por fim, (IV) inibidores de integrase (INI), que bloqueiam a atividade da enzima integrase, evitando a integração do do vírus no DNA do hospedeiro(BANDEIRA et al., 2017; GIR; VAICHULONIS; OLIVEIRA, 2005; PAU; GEORGE, 2014; RIBERA et al., 2011).

A associação entre a EM e o HIV já vem sendo descrita desde 1989(BERGER et al., 1989),entretanto, há poucos anos estão sendo realizados estudos que levantam a hipótese do efeito protetor observado do HIV no desenvolvimento da EMem virtude da imunossupressão causada pelo vírus e de um possível tratamento comARVs, já que o desenvolvimento da doença foi associado a HERVs(BRÜTTING et al., 2017; NEXØ et al., 2013; NISSEN et al., 2013). A combinação de ARVs de diferentes classes é usada para otimizar o tratamento da infecção por HIV e provavelmente age inibindoHERVs, que por consequência previnem o desenvolvimento da EM ou atuam na diminuição dos seus sintomas (GOLD et al., 2015; MARUSZAK et al., 2011).

\section{Evolução Clínica da Esclerose Múltipla}

Lublin etal., (LUBLIN; REINGOLD, 1996) observando que não havia um consenso na definição e terminologia que deveria ser usado para descrever os sintomas dos subtipos de EM, decidiram padronizar sua terminologia, o que poderia facilitar e ampliar o entendimento da doença e definir seu curso clínico. Foram então, estabelecidos os Critérios de McDonald para diagnóstico da EM. A EM se apresenta em surtos e de diferentes formas:a remitente recorrente (RR), na qual os portadores da doença são acometidos por episódios com sintomas da desmielinização como neurite óptica, seguido de remissão, podendo ou não deixar sequelas; a forma secundariamente progressiva (SP), que tem seus surtos com piora gradual com ou sem exarcebações agudas durante sua progressão; a forma progressiva recorrente (PR) que tem como característica a progressão desde o início, intercalando os surtos e podendo ou não ter recuperação total; a forma primariamente progressiva (PP), na qual não há os episódios de surto e remissão apresentando, então, progressão contínua. Como sintomas da desmielinização causada pela doença pode-se citar a neurite óptica unilateral, fadiga, dor aguda e/ou crônica, perda total ou parcial das funções fisiológicas, diminuição da sensibilidade tátil e motricidade em uma ou mais partes do corpo e falta de coordenação de movimentos musculares voluntários(GOLD et al., 2010; LUBLIN et al., 2014). Supõe-se que antígenos presentes na mielina, substância lipídica e proteica que recobre e protege o axônio, assim como acelera a transmissão do impulso nervoso, sejam apresentados às células T pelos astrócitos, macrófagos e microglia, levando a um ataque imunológico ao complexo mielina - oligodendrócito. 0 resultado dessa resposta inflamatória é a deterioração da mielina, com possível destruição de neurônios e axônios. A produção excessiva de anticorpos no SNC é uma das principais características da EM, sendo detectada no líquido cefalorraquidiano (LCR) a elevação de bandas oligoclonais e imunoglobulina G (IgG) (HEMMER; KERSCHENSTEINER; KORN, 2015; VAN DER VUURST DE VRIES et al., 2018).

\section{Retrovírus Endógenos Humanos}

A família de retrovírus é ampla e diversificada, a qual os vírus de RNA têm capacidade de reversão de seus genomas para DNA para em seguida se integrar ao genoma do hospedeiro. Nos retrovirus exógenos, a transmissão é horizontal e o vírus permanece infeccioso. Já nos retrovirus endógenos podem se tornar fixos nos indivíduos, sendo transmitidos de forma vertical, podendo ser herdadas através de gerações(ESCALERA-ZAMUDIO; GREENWOOD, 2016).Compondo cerca de 8\% do genoma humano, os HERVs possuem por volta de 30 a 50 diferentes famílias, com cerca de 200 subgrupos, resultados de integrações com retrovírus exógenos durante a evolução da nossa espécie, há milhões de anos atrás. Fatores ambientais e contato com outros vírus podem levar a ativação dos HERVs e consequente desenvolvimento de algumas doenças autoimunes, como EM e artrite reumatoide (DEWANNIEUX; HEIDMANN, 2013; EMMER; STAEGE; KORNHUBER, 2014; P. RYAN, 2011).

Existem duas famílias de retrovírus mais estudadas devido a um alto potencial de patogenicidade em humanos: a família de HERV-K, que está ligada ao desenvolvimento de neoplasias e esclerose lateral amiotrófica e a família HERV-W, relacionada ao desenvolvimento da EM(IBBA et al., 2018).Com diversas adaptações ocorrendo durante milhares de anos, alguns HERVs desenvolveram um papel importante para o ser humano. 0 subtipo HERV-W/Sincitina-1 é mediador na formação 
do sinciciotrofoblasto no início da gravidez. No entanto também pode servir como mediador imunopatogênico, sendo a proteína HERV-Wenv uma das possíveis responsáveis pelo desenvolvimento da EM (DOLEI, 2018).

O HERV-W foi descoberto em virtude de sua conexão com a EM. Em culturas de células de macrófagos de pacientes com EMvárias partículas semelhantes a retrovírus com atividade de transcriptase reversa (RT) foram detectadas e receberam o nome de retrovírus de esclerose múltipla (MSRVs). Em função da natureza retroviral do MSRV, pensava-se originalmente que o MSRV tinha uma origem viral exógena.

As similaridades filogenéticas e experimentais entre MSRV eHERVsforam descobertas, levando muitos laboratórios a procurar a família HERV específica da qual o MSRV pertencia. Usando a sequência de consenso para extensões de RT retroviral e "panretro" RT-PCR da região pol de MSRV (RNA retroviral), a descoberta de um HERV com gag, pol e env foi possível(SCHMITT et al., 2013).

Considerando a constante evolução científica e o desenvolvimento de novos estudos na perspectiva de minimizar os sintomas da esclerose múltipla, bem como possíveis explicações para os dados referidos, entende-se que a imunodeficiência causada pelo HIV possa ser um coadjuvante para o tratamento do desenvolvimento da EM. Da mesma forma, os ARVs também podem estar reprimindo outros vírus que podem estar associados com o desenvolvimentoda EM(GOLD et al., 2015; NEXØ et al., 2013). O presente estudo teve como objetivo avaliar se ARVs podem atenuar os sintomas causados pela EM, assim como avaliar as principais sintomatologias da esclerose múltipla, de acordo com os dados descritos na literatura.

\section{METODOLOGIA}

O estudo foi realizado através de uma revisão da literatura, utilizando como ferramenta embasadora materiais já publicados sobre o tema; livros, artigos científicos, e publicações periódicas. Foram revisadas as bases de dados PubMed (National Library of Medicine), Scielo (Sientific Eletronic Library Online), Lilacs (Litera- tura Latino Americana e do Caribe em Ciências da Saúde), além de documentos oficiais como dados da Organização Mundial da Saúde, Federação Internacional de Esclerose Múltipla e Ministério da Saúde. Outros trabalhos que constavam na lista de referências dos artigos encontrados foram utilizados como leitura suplementar. 0 levantamento bibligráficofoi realizadoentreagosto de 2017 e dezembro de 2018 e os termos utilizados para busca foram: "terapia antirretroviral", "agentesantirretrovirais", “esclerose múltipla”, "HIV”, “agentes anti-HIV", "retrovírus endógenos", "retrovírus endógenos humanos" bem como a combinação entre eles nos idiomas: português, inglês e espanhol. Não houve limite de ano para busca de publicação e todos os tipos de artigos foram contemplados devido à escassez de manuscritos nesta temática.

\section{RESULTADOS E DISCUSSÃO}

Os sinais e sintomas clínicos da EM são variáveis e podem resultar no envolvimento de vias sensitivas, motoras, visuais e do tronco encefálico(GARG; SMITH, 2015). 0 tratamento é usualmente realizado através de fármacos imunossupressores e imunomoduladores, com foco na redução dos surtos, entretanto, já foi observado que pacientes com HIV, emterapia com medicamentos antirretrovirais podem reprimir a sintomatologia da EM(GOLD et al., 2015; NEXØ et al., 2013). Na presente revisão, foram avaliadas 52 bibliográficas, sendo: 1 livro, 1 documento da Federação Internacional de Esclerose Múltipla, 1 documento do Ministério da Saúde e 49 artigos. Dos manuscritos avaliados, 4citaram os medicamentos antirretrovirais para HIV utilizados nos pacientes portadores de EM, referindo a melhora observado no quadro clínico dos pacientes tratados para a EM. Estes estudos estão com os principais resultados descrito na tabela 1.De forma geral, além dos estudos descritos na tabela, na busca bibliográfica ficou evidente que o tipo mais comum de EM presente foi a EM-RR, que consiste seus sintomas em surtos e remissão. (CHIN, 2015; GONZÁLEZ-DUARTE et al., 2011; MARUSZAK et al., 2011; NEXØ et al., 2013). 
Tabela 1: Relação de estudos com antirretrovirais e principais resultados.

\begin{tabular}{|c|c|c|}
\hline ESTUDO & ARVs UTILIZADOS & $\begin{array}{l}\text { RESULTADOS APÓS INICIO DO } \\
\text { TRATAMENTO COM ARVS }\end{array}$ \\
\hline Maruszak et al., 2011 & $\begin{array}{l}\text { Nevirapina, Estavudina, } \\
\text { Didanosina, Abacavir, lamivudina, } \\
\text { Ritonavir, Indinavir, Saquinavir, } \\
\text { associação Atazanavir/Ritonavir, } \\
\text { associação lopinavir/Ritonavir }\end{array}$ & $\begin{array}{l}\text { Remissão dos sintomas clínicos da EM } \\
\text { como: incontinência fecal e urinária, } \\
\text { neurite óptica, hemiparesia, parestesia, } \\
\text { dores de cabeça e fadiga. } \\
\text { Acompanhamento do uso de ARVs entre } \\
\text { os anos de } 1996 \text { e } 2010 \text {. }\end{array}$ \\
\hline $\begin{array}{l}\text { Joshua Chalkley\& Joseph } \\
\text { R. Berger, } 2014\end{array}$ & $\begin{array}{l}\text { Associação Tenofovir/ } \\
\text { Emtricitabina, Nelfinavir }\end{array}$ & $\begin{array}{l}\text { Ausência de progressão } \\
\text { dadesmielinização, normalização de } \\
\text { tônus, sensibilidade, força e coordenação } \\
\text { motoras. Acompanhamento do uso de } \\
\text { ARVs entre os anos de } 2006 \text { e } 2013 \text {. }\end{array}$ \\
\hline $\begin{array}{l}\text { Delgado SR, Maldonado } \\
\text { J, Rammohan KW, } 2014\end{array}$ & $\begin{array}{l}\text { Ritonavir, atazanavir, associação } \\
\text { tenofovir/emtricitabina, abacavir/ } \\
\text { lamivudina }\end{array}$ & $\begin{array}{l}\text { Melhora do estado de falta de } \\
\text { deambulação para uma deambulação } \\
\text { quase totalmente sem ajuda com melhora } \\
\text { também da força motora, resolução de } \\
\text { incontinência urinária e fecal, melhora } \\
\text { significativa da desmielinização. } \\
\text { Acompanhamento do uso de ARVs entre } \\
\text { os anos de } 2012 \text { e } 2013 \text {. }\end{array}$ \\
\hline Skarlis et al., 2017 & $\begin{array}{l}\text { Atripla (combinação de Efavirenz/ } \\
\text { Emtricitabina/Tenofovir) }\end{array}$ & $\begin{array}{l}\text { Estabilidade clínica e neurorradiológica } \\
\text { após exame de ressonância magnética } \\
\text { detectar diplopia horizontal esquerda e } \\
\text { lesões multifocais da substância branca } \\
\text { no cérebro e na coluna cervical. } \\
\text { Acompanhamento do uso de ARVs entre } \\
\text { os anos de } 2014 \text { e } 2015 \text {. }\end{array}$ \\
\hline
\end{tabular}

ARVs: Medicamentos antirretrovirais; EM: esclerose múltipla.

Em 1989 Berger et al., relatou sete homens adultos com doença remitente-recorrente que afetava a substância branca do cérebro, indistinguível de EM e ocorrendo em associação a soropositividade de HIV-1. Foram obtidas amostras histopatológicas do SNC de três pacientes, sendo dois por biópsia e um por necrópsia, todos consistentes com o diagnóstico de EM. Em todos os pacientes, os sintomas neurológicos precederam o começo da imunossupressão clinicamente evidente. Seis dos pacientes descritos continuaram com sintomas neurológicos rescidivantes.

No ano de 2002 uma criança do sexo masculino, com 8 anos e 9 meses foi avaliada com convulsões que ocorreram no intervalo de dois dias, durando cerca de $5 \mathrm{mi}$ nutos, não apresentando febre nem sinais de doenças sistêmicas. A criança nasceu de mãe soropositiva para HIV-1 e a mesma, não recebeu tratamento durante a gravidez, sendo feito o diagnóstico de infecção congênita de HIV-1.Testes laboratoriais revelaram baixa contagem de linfócitos T CD4, T CD8 normais, baixa razão CD4/ CD8 e alta contagem de carga viral. Foi realizado o exame de ressonância magnética revelando uma massa no lobo parietal direito e biópsia do cérebro revelando áreas de desmielinização e infiltração de macrófagos. Testes para micobactéria, fungo e John Cunningham vírus (JC vírus) deram resultados negativos e seu diagnóstico foi de doença desmielinizante. Foi prescrita medicação para convulsão, sendo descontinuada em seguida, já que a criança tornou-se assintomática. Nesse caso não foramadministrados esteroides. Aos 10 anos, voltou ao hospital com dor e perda de visão no olho direito por aproximadamente duas semanas. Com novas imagens feitas por ressonância magnética, foram revelados mais lesões cerebrais e dessa vez foi feita eletroforese de LCR revelandoa formação de bandas oligoclonais(FACCHINI; HARDING; WALDRON, 2002).

Duránet al. (DURÁN et al., 2004)relatou o caso de um homem de 32 anos de idade diagnosticado com HIV- 
1 em março de 2002, iniciando tratamento com ARVs logo em seguida. Em maio do mesmo ano foi admitido no hospital com perda visual em seu olho esquerdo, com duração de três dias. Em ressonância magnética foram reveladas lesões compatíveis com EM. Depois de administrado medicamento corticoesteroide por três dias, o paciente teve a recuperação de sua visão. Portanto, Durán, Berger, Facchini levantaram a hipótese de a infecção pelo HIV possa ser um dos fatores para o desenvolvimento da EM, mas não se sabe ainda a causa dessa possível associação.

Em contrapartida, há relatos de casos descritos na literatura supondo que ARVs usados para tratar a infecção por HIV possa estar atenuando a sintomatologia da EM, quando há o diagnóstico simultâneo de EM e confirmação da soropositividade para HIV nesses pacientes. Maruzsaket al. (MARUSZAK et al., 2011)citouum relato de caso onde o paciente apresentou sintomas neurológicos compatíveis com os da EM, decorrendo por cerca de uma semana manifestações como cegueira bilateral, parestesia e fraqueza do lado esquerdo, assim como surdez e paresia do lado esquerdo da língua. Foram feitos exames de imagem e análise do líquido cefalorraquidiano (LCR), não sendo estabelecido causa num primeiro momento. 0 paciente foi liberado com uso de interferon beta, tendo o tratamento interrompido em seguida devido aos efeitos colaterais. Vários meses após o episódio sintomático, foi confirmada a soropositividade para o HIV desse paciente. Após a confirmação da soropositividade, o sistema imunológico do paciente se manteve estável nos dez anos seguintes, tendo início a terapia antirretroviral em 1996. Com o início do tratamento os sintomas relacionados a EM foram cessando, não apresentando novas crises. Até 2011 esse tinha sido o primeiro caso de paciente diagnosticado com EM e tratado com ARVs com resolução dos sintomas.

Estudo realizado por González-Duarte et al. (GONZÁLEZ-DUARTE et al., 2011),apresentou o caso de um homem de 43 anos diagnosticado portador do HIV em 1996, tendo iniciado a terapia antirretroviral naquele ano. Cinco anos após, o paciente apresentou um episódio de tontura, parestesia do braço e da perna esquerda e fraqueza no braço esquerdo. Suspeitou-se de toxoplasmose, sendo o paciente medicado e total recuperação dos sintomas. Após um ano teve mais um evento de vertigem repentina com fraqueza do lado esquerdo do corpo, foi medicado e teve recuperação espontânea completa. No ano seguinte apresentou a terceira manifestação neurológica, agora com fraqueza e parestesia no braço e perna esquerda. Dessa vez não foi lhe dado nenhum tratamento e teve sua recuperação espontânea completa.

Delgado et al. (DELGADO; MALDONADO; RAMMOHAN, 2014) descreveu o caso onde um homem afro-americano de 46 anos apresentou perda visual progressiva e fraqueza progressiva da extremidade inferior esquerda com disfunção urinária por três semanas. Após medicado com prednisona via oral por cinco dias, o paciente recebeu alta da reabilitação usando um andador. Imediatamente começou a terapia com ARVs. Três meses depois de iniciada a terapia antirretroviral, voltou ao consultório usando apenas uma bengala para se locomover, porém a perda visual permaneceu. Um ano depois já estava andando sem auxílio, mas ainda sem a recuperação visual. Até o fim do estudo não houve mais déficits neurológicos.

Em 2001, um homem de 32 anos de El Salvador, apresentou neurite óptica no olho esquerdo progredindo à não percepção da luz. Logo houve melhora sem tratamento. Após três meses, a neurite óptica desenvolveu-se no olho direito, resolvido sem terapia. Pouco tempo depois desenvolveu paresia facial e dos membros direitos melhorando após algumas semanas de administração intravenosa de glicocorticoides. Após a realização de exame de ressonância magnética craniana, foi possível observar lesões características de EM. No mesmo período o paciente teve diagnóstico positivo para o vírus HIV. Até 2006 o paciente não havia apresentado mais nenhum sintoma neurológico, porém em julho daquele ano desenvolveu neurite óptica esquerda associada a hemiparesia esquerda e anormalidades hemisensoriais. Em seguida foi administrado um medicamento imunomodulador por cerca de dois meses. Após isso não foi mais administrado medicamento imunomodulador para tratamento da EM, continuando apenas com os ARVs e sem recorrência de sintomas neurológicos, sendo o paciente examinado mais recentemente em maio de 2013, de acordo com os autores(CHALKLEY; BERGER, 2014).

Nesses casos apresentados foram feitos testes incluindo reação em cadeia da polimerase (PCR) para $M i$ cobacteriumtuberculosis, Citomegalovírus, Epstein-Barr vírus, Herpes simplex, John Cunningham vírus (JC 
vírus) sendo todos os resultados negativos. Pesquisa de bandas oligoclonais foi feita no LCR com resultado positivo, proteína básica da mielina e índice de IgG aumentadas, resultados indicativos para diagnóstico da EM. Exame de ressonância magnética também foi feito em todos os casos, indicando lesões cerebrais características da doença(SKARLIS et al., 2017).

Foi sugeridaa relação do desenvolvimento da EM com os HERVs e que essa associação pode resultar na atenuação dos sintomas da EM com o tratamento de ARVs, que é usada para tratar pacientesHIV-soropositivos (CHALKLEY; BERGER, 2014; GOLD et al., 2015; MARUSZAK et al., 2011). Com essas informações, foi decidido investigar a incidência de EM em uma coorte dinamarquesa de pacientes HIV-soropositivos (5018 pacientes) e compararam com controles (50149 indivíduos), sendo eles pareados por idade e sexo. Os dados foram levantados através do Registro Nacional Dinamarquês de Pacientes entre 1994 e 2011, que cobre todos os hospitais localizados no país, que está ligado ao Registro Civil e ao registro de EM da Dinamarca. 0 estudo não obteve significância estatística devido a um baixo número de pacientes que desenvolveram EM nos grupos pesquisados, porém sugeriu que houve uma diminuição do risco de desenvolvimento da EM em pacientes HIV-soropositivos, sendo plausível esse fato devido ao uso de ARVs desses pacientes(NEXØ et al., 2013).

Anand e Saylor(ANAND; SAYLOR, 2018), citaram que há outra possível explicação, onde a imunodeficiência induzida pelo HIV pode prevenir o desenvolvimento da EM. Um estudo maior foi feito levantando dados daEstatistica dos Hospitais Ingleses, sendo um estudo de coorte comparativo, identificando cerca de 21207 pacientes HIV-soropositivos. Mostrou-se que pacientes com HIV tem uma diminuição do risco de desenvolver EM(GOLD et al., 2015). A diminuição dos sintomas parece estar ligada à imunossupressão causada pelo vírus HIV, assim como o uso deARVs. Na comparação do número de linfócitos CD4+ com grupos HIV soropositivos e CD4+é similar entre grupos HIV e EM em tratamento, como esperado pelos autores, porém é diferente entre os grupos com HIV e EM não tratados. Os autores do estudo concluíram que o HIV pode contribuir com a dimuição dos sintomas causados através da imunossupressão que o vírus induz(KOUDRIAVTSEVA et al., 2017).
Em 2003, um paciente do sexo masculino, com 24 anos foi diagnosticado com EM, tendo os sintomas típicos da doença, com a recuperação dos sintomas espontaneamente. Durante a década seguinte, manifestou outros episódios de ataques neurológicos, com a administração de medicamentos corticoesteroides. Em 2014 o paciente foi diagnosticado com HIV, iniciando a terapia antirretroviral imediatamente. Depois de três anos iniciada a terapia antirretroviral o paciente demonstrou levar uma vida funcional e ativa (SKARLIS et al., 2017).

Considerando as informações obtidas ao longo dos anos sobre ARVs possivelmente estarem amenizando sintomas da EM, foi iniciado um ensaio clínico com 20 participantes inscritos em fase inicial da EM, sendo observados por três meses sem o uso de qualquer medicamento.Decorrido este período, os pacientes receberam $400 \mathrm{mg}$ de um medicamento inibidor de integrasedenominadoraltegravir, um ARV, duas vezes ao dia. A dose e frequência do medicamento foi escolhida considerando que esse é um dos medicamentos licenciados para tratar a infecção por HIV, mas ainda não há dados sobre esse medicamento sendo usado no tratamento de EM-RR. Todos os pacientes completaram os seis meses de testes. 0 estudo concluiu que não obteve impacto nesses pacientes com EM ativa. Esse resultado pode ser devido ao tratamento monoterápico com ARV, assim como pelo curto período de tratamento com a medicação(GOLD et al., 2018).

\section{CONCLUSÃO}

A pesquisa cumpriu com os objetivos aos quais se propôs inicialmente, possibilitando compilar alguns dados, dos poucos estudos disponíveis, referente à interferência dos medicamentos antirretrovirais nos sintomas da esclerose múltipla. No presente estudo fica evidente que os medicamentos antirretrovirais podem auxiliar na redução dos sintomas causados pela esclerose múltipla. Este estudo predispõe a necessidade de estudos posteriores sobre a relação do uso de ARVs no tratamento sintomatológico da esclerose múltipla, bem comoinvestigar se esses medicamentos podem reduzir a expressão de HERVs e consequentemente diminuir a frequência de casos de EM. Assim, espera-se que os resultados desta pesquisa possam contribuir para o desenvolvimento de novos estudos e que possam ser somados ao conhecimento sobre a questão aqui apresentada. 


\section{REFERÊNCIAS}

ANAND, P.; SAYLOR, D. Multiple sclerosis and HIV: a case of multiple sclerosis-immune reconstitution inflammatory syndrome associated with antiretroviral therapy initiation. International Journal of STD \& AIDS, v. 29, n. 9, p. 929-932, 21 ago. 2018.

BANDEIRA, A. C. P. C. S. et al. Antiretroviral changes during the first year of therapy. Revista da Associação Médica Brasileira, v. 63, n. 7, p. 606-612, 2017.

BERGER, J. R. et al. Multiple sclerosis-like illness occurring with human immunodeficiency virus infection. Neurology, v. 39 n. 3, p. 324-324, 1 mar. 1989.

BRASIL.LEI № 9.313, DE 13 DE NOVEMBRO DE 1996. Dispõe sobre a distribuição gratuita de medicamentos aos portadores do HIV e doentes de AIDS. Disponível em: <www.planalto.gov br/ccivil_03/Leis/L9313.htm>. Acesso em 6 jan. 2021.

BRÜTTING, C. et al. Cooccurrences of Putative Endogenous Retrovirus-Associated DiseasesBioMed Research International, 2017.

CALCAGNO, A.; DI PERRI, G.; BONORA, S. Treating HIV Infection in the Central Nervous System. Drugs, v. 77, n. 2, p. 145-157, 2017.

CARDOSO, F. A. G. Atuação Fisioterapêutica Na Esclerose Múltipla Forma Recorrente-Remitente Fisiotherapy in Recurrent-Remittent Multiple Sclerosis. Revista movimenta, v. 3, n. 2, p. 69-75, 2010.

CHALKLEY, J.; BERGER, J. R. Multiple sclerosis remission following antiretroviral therapy in an HIV-infected man. Journal of NeuroVirology, v. 20, n. 6, p. 640-643, 1 dez. 2014.

CHIN, J. H. Multiple sclerosis and HIV-1 infection: case report of a HIV controller. Journal of NeuroVirology, v. 21, n. 4, p. 464-467, 24 ago. 2015

COELHO, L. P. O. Predição do tropismo viral do HIV-1 utilizando plasma e célula em amostras de sangue de pessoas vivendo com HIV / AIDS. 2013

COSTA, C. R. Manifestações bucais da AIDS e o perfil de mutações e de resistência do HIV em pacientes experimentando falha terapêutica. 2013.

DE ALENCAR SANTOS JÚNIOR, J. G. et al. ESCLEROSE MÚLTIPLA: RELATO DE CASO E CRITÉRIOS DE DIAGNÓSTICO. Revista de Epidemiologia e Controle de Infecção, v. 6, n. 1, p. 4-6, 1 mar. 2016

DELGADO, S. R.; MALDONADO, J.; RAMMOHAN, K. W. CNS demyelinating disorder with mixed features of neuromyelitis optica and multiple sclerosis in HIV-1 infection. Case report and literature review. Journal of NeuroVirology, v. 20, n. 5, p. 531-537, 1 out. 2014.
DEWANNIEUX, M.; HEIDMANN, T. Endogenous retroviruses: acquisition, amplification and taming of genome invaders. Current Opinion in Virology, v. 3, n. 6, p. 646-656, dez. 2013.

DOLEI, A. The aliens inside us: HERV-W endogenous retroviruses and multiple sclerosis. Multiple Sclerosis Journal, v. 24, n 1, p. 42-47, 8 jan. 2018.

DURÁN, E. et al. Multiple sclerosis-like illness in a HIV-1 patient. Journal of Neurology, v. 251, n. 9, p. 1142-1144, set. 2004.

EMMER, A.; STAEGE, M. S.; KORNHUBER, M. E. The Retrovirus/ Superantigen Hypothesis of Multiple Sclerosis. Cellular and Molecular Neurobiology, v. 34, n. 8, p. 1087-1096, 20 nov. 2014.

ESCALERA-ZAMUDIO, M.; GREENWOOD, A. D. On the classification and evolution of endogenous retrovirus: human endogenous retroviruses may not be 'human' after all. APMIS, v. 124, n. 1-2, p. 44-51, jan. 2016.

FACCHINI, S. A.; HARDING, S. A.; WALDRON, R. L. Human immunodeficiency virus-1 infection and multiple sclerosis-like illness in a child. Pediatric Neurology, v. 26, n. 3, p. 231-235, mar. 2002.

FORESTO, J. S. et al. Adesão à terapêutica antirretroviral de pessoas vivendo com HIV / aids em um município do interior paulista. Revista Gaúcha de Enfermagem, v. 38, n. 1, p. 1-7, 2017.

GARG, N.; SMITH, T. W. An update on immunopathogenesis, diagnosis, and treatment of multiple sclerosis. Brain and Behavior, 2015.

GIR, E.; VAICHULONIS, C. G.; OLIVEIRA, M. D. DE. Adhesion To Anti-Retroviral Therapy By Individuals With Hiv / Aids. Rev Latino-am Enfermagem, v. 13, n. 5, p. 634-641, 2005.

GOLD, J. et al. HIV and lower risk of multiple sclerosis: beginning to unravel a mystery using a record-linked database study. Journal of Neurology, Neurosurgery \& Psychiatry, v. 86, n. 1, p. 9-12, jan. 2015.

GOLD, J. et al. A phase II baseline versus treatment study to determine the efficacy of raltegravir (Isentress) in preventing progression of relapsing remitting multiple sclerosis as determined by gadolinium-enhanced MRI: The INSPIRE study. Multiple Sclerosis and Related Disorders, v. 24, p. 123-128, ago. 2018.

GOLD, R. et al. Evolving expectations around early management of multiple sclerosis. Therapeutic Advances in Neurological Disorders, v. 3, n. 6, p. 351-367, 2010.

GONZÁLEZ-DUARTE, A. et al. Multiple sclerosis typical clinical and MRI findings in a patient with HIV infection. Journal of NeuroVirology, v. 17, n. 5, p. 504-508, 1 out. 2011. 
HEMMER, B.; KERSCHENSTEINER, M.; KORN, T. Role of the innate and adaptive immune responses in the course of multiple sclerosis. The Lancet Neurology, v. 14, n. 4, p. 406-419, 2015.

IBBA, G. et al. Disruption by SaCas9 Endonuclease of HERV-Kenv, a Retroviral Gene with Oncogenic and Neuropathogenic Potential, Inhibits Molecules Involved in Cancer and Amyotrophic Lateral Sclerosis. Viruses, v. 10, n. 8, p. 412, 7 ago. 2018.

KANG, J.-H. et al. Increased Risk of Multiple Sclerosis Following Herpes Zoster: A Nationwide, Population-Based Study. The Journal of Infectious Diseases, v. 204, n. 2, p. 188-192, 15 jul. 2011

KOUDRIAVTSEVA, T. et al. HIV and decreased risk of multiple sclerosis: role of low CD4+ lymphocyte count and male prevalence. Journal of NeuroVirology, v. 23, n. 1, p. 147-151, 2017.

LERAY, E. et al. Epidemiology of multiple sclerosis. Revue Neurologique, v. 172, n. 1, p. 3-13, 2016

LUBLIN, F. D. et al. Defining the clinical course of multiple sclerosis: the 2013 revisions. Neurology, v. 83, n. 3, p. 278-286, 2014.

LUBLIN, F. D.; REINGOLD, S. C. Defining the clinical course of multiple sclerosis : Neurology, v. 46, p. 907-911, 1996.

MALIK, S.; EUGENIN, E. A. Mechanisms of HIV Neuropathogenesis: Role of Cellular Communication Systems. Current HIV research, v. 14, n. 5, p. 400-411, 2016.

MARUSZAK, H. et al. Could antiretroviral drugs be effective in multiple sclerosis? A case report. European Journal of Neurology, v. 18, n. 9, p. e110-e111, set. 2011.

MECHELLI, R. et al. Epstein-Barr virus genetic variants are associated with multiple sclerosis. Neurology, v. 84, n. 13, p. 1362-1368, 31 mar. 2015.

NEXØ, B. A. et al. Treatment of HIV and Risk of Multiple Sclerosis. Epidemiology, v. 24, n. 2, p. 331-332, mar. 2013.

NISSEN, K. K. et al. Endogenous retroviruses and multiple sclerosis-new pieces to the puzzle. BMC Neurology, v. 13, n. 1, p. 111, 2013.

OKOYE, A. A.; PICKER, L. J. CD4+ T-Cell Depletion In Hiv Infection: Mechanisms Of Immunological Failure. Immunological Reviews, v. 254, n. 1, p. 54-64, 2013.

P. RYAN, F. Human Endogenous Retroviruses in Multiple Sclerosis: Potential for Novel Neuro-Pharmacological Research. Current Neuropharmacology, v. 9, n. 2, p. 360-369, 1 jun. 2011.
PARHAM, P. O Sistema Imune. 3. ed. Porto Alegre: Artmed, 2011

PAU, A. K.; GEORGE, J. M. Antiretroviral therapy: Current drugs. Infectious Disease Clinics of North America, v. 28, n. 3, p. 371-402, 2014.

POLEJACK, L.; SEIDL, E. M. [Monitoring and evaluation of adherence to ARV treatment for HIV/AIDS: challenges and possibilities]. Cien Saude Colet, 2010

RIBERA, E. et al. Characteristics of antiretroviral drugs. Enfermedades Infecciosas y Microbiologia Clinica, v. 29, n. 5, p 362-391, 2011.

SÁ, M. J. Physiopathology of symptoms and signs in multiple sclerosis. Arquivos de neuro-psiquiatria, v. 70, n. 9, p. 73340, 2012.

SCHMITT, K. et al. Comprehensive Analysis of Human Endogenous Retrovirus Group HERV-W Locus Transcription in Multiple Sclerosis Brain Lesions by High-Throughput Amplicon Sequencing. Journal of Virology, v. 87, n. 24, p. 13837-13852, 15 dez. 2013.

SKARLIS, C. et al. Multiple sclerosis and subsequent human immunodeficiency virus infection: A case with the rare comorbidity, focus on novel treatment issues and review of the literature. In Vivo, v. 31, n. 5, p. 1041-1046, 1 set. 2017.

THOMPSON, A. J.; BANEKE, P. Multiple Sclerosis International Federation (MSIF) Design and editorial support by Summers Editorial \& Design Graphics by Nutmeg Productions Printed by Modern Colour Solutions. 2013.

TILBERY, C. P. et al. Efeitos adversos no tratamento da Esclerose Múltipla com drogas imunomoduladoras - Experiência em 118 casos. Revista Neurociencias, v. 17, n. 3, p. 220-225, 2009 .

VAN DER VUURST DE VRIES, R. M. etal. Application of the 2017 Revised McDonald Criteria for Multiple Sclerosis to Patients with a Typical Clinically Isolated Syndrome. JAMA Neurology, v. 75, n. 11, p. 1392-1398, 2018.

WALLIN, M. T. et al. Global, regional, and national burden of multiple sclerosis 1990-2016: a systematic analysis for the Global Burden of Disease Study 2016. The Lancet Neurology, v. 18, n. 3, p. 269-285, mar. 2019

WILDNER, P.; SELMAJ, K. W. Multiple sclerosis: Skin-induced antigen-specific immune tolerance. Journal of Neuroimmunology, v. 311, p. 49-58, 2017. 